\title{
ANYTIME, ANYPLACE AND THE COMMUNITY COLLEGE: TEN EMERGING INSIGHTS
}

Mark David Milliron, Ph.D.

President and CEO of League for Innovation in the Community College

4505 East Chandler Boulevard

Suite 250

Phoeniz, AZ 85048

Phone: (480) 705-8200; Fax (480) 705-8201

Mary Prentice, Ph.D.

Assistant Professor

Educational Management and Development Department

New Mexico State University

P.O. Box 30001, MSC 3N

Las Cruces, NM 88003-8001

Phone: (505) 646-2962; Fax (505) 646-4767

\section{INTRODUCTION}

Community colleges are a vital part of the larger higher education community in the United States and increasingly around the world. The more than 1,100 U.S. community colleges - not to mention the hundreds of like institutions internationally - have evolved into dynamic, comprehensive institutions that are often known for their resourcefulness in using any available tool or technique to improve and expand learning [1], [2], [3], [4]. From the early days of correspondence courses to the "colleges without walls" movement of the 1970s and 1980s, community college educators have demonstrated a commitment to extending the reach of education in their continuing efforts to make a difference for students and communities.

In today's higher education world, asynchronous learning is the power tool. Moreover, the associated techniques for using asynchronous learning to support in-class and online instruction are bringing learning to life in new and exciting ways. This edition of the Journal of Asynchronous Learning Networks examines the role of these anytime, anyplace tools with a special focus on the characteristics of the community college movement - particularly the access, affordability, and outreach elements. Readers are treated to explorations of demographic trends, technological tools, and change-management strategies from well known researchers and practitioners. The conversation often ranges beyond community college, and that is with purpose. Community colleges are part of the broader family of education as well as a piece of the social and political fabric of the communities that they serve and thus deserve to be explored in this more complete context.

In Using Asynchronous Learning in Redesign: Reaching and Retaining the At-Risk Student, Carol Twigg draws on her work with The Pew Charitable Trust project on curriculum redesign to explore the use of asynchronous learning by pacesetter institutions, with a particular focus on their use of these tools 
to improve retention and service to at-risk populations. Several leading community colleges are featured in case studies along with their university colleagues, all demonstrating systemic efforts to redesign instruction.

Next, Linda Thor and Carol Scarafiotti, President and Dean of Instruction respectively of Rio Salado College (AZ), detail their compelling journey toward Mainstreaming Distance Learning Into the Community College. From their beginning work with TQM, Learning Organizations, early e-learning adventures, and their more mature initiatives, readers take a behind-the-scenes look at a community college that leverages asynchronous learning, along with a host of other strategies, to "astound students."

Academic Redesign: Accomplishing More With Less is offered from the perspective of a services corporation, Collegis, that works with community colleges and universities to implement Asynchronous Learning tools. William Graves, Vice Chairman and Chief Academic Officer of Collegis, reflects on this work and offer perspectives from the vendor community with a special focus on accessibility, affordability, and accountability.

If It Ain't Broke, Improve It: Thoughts on Engaging Education for Us All explores the use of asynchronous tools, as well as a host of others, that are useful in making learning more engaging for all. In this article, Steve Gilbert, President of the TLT Group, draws on his work with the Teaching and Learning and Technology Group (www.tltgroup.org) and their hundreds of members to outline key higher education issues, visions worth pursuing, and strategies and tools for working toward the greater good that education inspires.

In another case study, Richard Rhodes, President of El Paso Community College (EPCC) and Barbara Walker, Major Accounts Manager for Cisco Systems, profile EPCC's strategic use of technology and asynchronous learning in The Orion Project: Connecting a Community. As one of the leading Hispanicserving community colleges in the country, EPCC has been particularly challenged to leverage asynchronous learning in supporting and promoting successful minority transition between education levels.

Putting a Little TLC Into Learning by Stella Perez, Senior Consultant for Online Initiatives with the League for Innovation in the Community College, includes an exploration of asynchronous learning and innovation as showcased in a multiyear Fund for the Improvement of Postsecondary Education (FIPSE) project (http://www.league.org/leaguetlc). This initiative is another example of the use of asynchronous learning tools to create outreach mechanisms to disseminate proven innovations to a community college field hungry for learning models that work.

The Weariness of the Flesh: Reflections on the Life of the Mind in the Era of Abundance is offered by Paul Gandel and Richard Katz from Educause, the largest technology association in the United States. Drawing on research conducted by the Educause Center for Applied Research and their National Learning Infrastructure Initiative, they place the use of asynchronous learning against the larger backdrop of the higher education field at large and point to some compelling considerations for educators living in this era of "abundance."

In the concluding article, The Road to DotCalm, League for Innovation President and CEO Mark Milliron draws on the work of key League initiatives surrounding the digital divide and consulting engagements with hundreds of colleges to offer thoughts about avoiding hazards on the road ahead for 
technology and learning. The article concludes this journal with a compelling call to diligently and calmly work toward broader inclusion in education as a prerequisite for life in an increasingly digital democracy.

\section{TEN EMERGING INSIGHTS}

As we reflect on these articles, we are struck by issues that point the way to further discussion and research. Moreover, when we combine these issues with the findings from the ongoing major trends study conducted every three years by the League for Innovation [5], [6], our vision of the road ahead for asynchronous learning becomes clearer. In short, as we travel onward toward the more advanced applications of asynchronous learning, we need to keep in mind the following emerging insights.

\section{A. Consider Many Best Ways}

While educators value their ability to hold on to complex ideas and explore experiments with a host of interacting variables, it is stunning how often discussion about learning models regresses into defending "the one best way." Based on the articles here, particularly Carol Twigg's, and our ongoing work with learning-centered education [4], [7], [8], [9], it is clear that there is not one best way to teach, reach, and learn-much less use asynchronous learning tools. The effectiveness of learning in person, online, or in any combination is predicated on a host of personal, professional, technical, and situational variables that make dictating the one best way to teach and learn about as useful as waxing poetic about the best haircut.

\section{B. Remember the Human Touch}

One of the most resounding findings and sentiments from the research and thought pieces we have reviewed is the need to remember that learning is a human enterprise. Ironically, it is often technology that brings the interaction back into learning by creating avenues for dialogue in large lecture venues through online discussions or simply via email. Still, as we rush down the road ahead, we have to be sure to slow down, look around, and bring our mindfulness and human orientation to the process. This call is echoed by the authors throughout this journal.

\section{Champion Digital Democracy}

Thomas Jefferson said that "if a Nation expects to live ignorant and free, it wants what never was and what never will be." This statement has never been truer than today in our world of hyperconnections; a world where gamblers, pornographers, and hate groups are the most lucrative purveyors of online tools [10], [11]. Programs like the one outlined by Rhodes and Walker in their Orion Project challenge us to think about embracing this role as a higher calling than simply bridging the digital divide. As a strategic planning team at Valencia Community College (www.valenciacc.edu) puts it in an effort to center their roles as community college educators in the modern world, "America starts here." It is our commitment to helping students access learning through technology and to embrace learning beyond technology-e.g., critical thinking, problem solving, decision making, global awareness, and community involvement- that may help them live not only well, but free.

\section{Learn for a Lifetime}

Part of making this digital democracy work is our broad embrace of learning for a lifetime. And it is not enough to learn about this technology, we need to learn with it to better understand its potential. Moreover, because of the "abundance" of learning and the tools to make it more accessible, we are 
blessed with easily adaptable mechanisms to bring learning to our fingertips. Call it professional development, career advancement, or personal growth - by any name, learning is now a lifetime activity. Gandel and Katz join in voice with Gilbert here to sound this call and to challenge us to embrace this insight.

\section{E. Integrate Your College}

Many colleges took bold steps to aggressively roll out online versions of their college, online degrees, or simply online offerings to their already robust distance learning programs. However, in this exuberant rush to innovate, many colleges created an almost separate college infrastructure that does not integrate well with the rest of their institution. Of course, this observation is specific to those institutions that have in-person operations. This "deal with the devil," as some presidents call it, was made to allow for growth and innovation without bureaucracy and tradition stifling the new and novel. The challenge is that students do not see nor care about this deal. Your college is one college to them. All they know is that these dual systems are cumbersome. They want a college where they can mix and match in person, online, and via hybrid options without needless runarounds or multiple registrations and fees. Rio Salado's story in this journal is one of the most compelling tales of building to end the segregation of online learning and bringing together asynchronous and synchronous tools - particularly cyberservices and call centers-into the mainstream of the institution.

\section{F. Welcome Dynamic Balance}

The cases outlined and the experiences recounted here of working in community colleges are replete with cues to the readers to pay attention to the culture of the college and strategies for implementation. We may choose the best technology tool, foster the most compelling asynchronous-learning partnership, or craft the most reasoned technology policy; still, if these are championed by true believers or attacked by caustic cynics, they can quickly be rendered impotent. It is clear that we are called to foster and support reasoned advocacy and thoughtful criticism and avoid the extremes. This means tempering our own hyperbole about the power of tools like asynchronous learning. It also means honoring the past as we move to the future. It is clear that many of the best practices long associated with teaching and learning also apply in the online and asynchronous worlds. Not surprisingly, organization, clarity, participation, interaction, stimulating different learning styles, multimodal assessment, and making cognitive connections between learning material and learner experience emerge as important for online and hybrid learning. Put simply, it is a dynamically balanced approach to organizational culture and strategic practice throughout research, planning, and implementation that can make or break our important efforts in asynchronous learning.

\section{G. Embrace Expanding Markets}

The Rio Salado College, Collegis, and Educause articles are wonderful wake-up calls to expanding markets. When it comes to asynchronous learning, there is little doubt that it can add much to our existing students' experiences. But even more important, especially for those who are champions of access like community college educators, asynchronous learning affords us the opportunity to reach out in new ways. The fears that online offerings are cannibalizing our campus programs have been calmed as most realize that students mix and match online and face-to-face learning experiences. And without the online learning experiences, many would not be attending at all. We are expanding the pie and opening our doors wider through online courses, programs, and degrees. Moreover, online workforce education options are providing training to those who could never have stopped their lives to obtain advanced certification or other, even basic skills such as team building or leadership training. 


\section{H. Dog the Details}

In addition to the opportunity that asynchronous learning offers, however, comes the added responsibility of dealing with difficult details. Security, financing, interoperability, and standards all challenge us on the road ahead. The authors here point the way to some compelling dialogues that we must have surrounding these issues. As our asynchronous and other technology systems become prime-time elements of our programs and services, we need to ensure that they are up to standards. This will likely mean treating this infrastructure much like our other major systems, more thorough planning, documented and systemic implementation, careful evaluation, and external audits.

\section{Put Learning First}

The new and novel are so intoxicating. However, the resounding call here is for us to use technology, not be used by it. Asking hard questions about whether or not asynchronous learning tools and technology in general are improving and expanding learning seems to be essential for us to be most effective with our educational programs and practice [8], [12], [10]. In essence, learning is our key Return On Investment (ROI) as Graves puts it. For those who put learning first, asking hard questions about the effectiveness of programs is a must. This hard-nosed perspective is at the heart of many of the cases outlined herein, not to mention the extensive initiatives of colleges participating in the League's Vanguard Learning College Project (http://www.league.org/league/projects/lcp/index.htm). Moreover, this perspective helps give focus to efforts to consider the many best ways, remember the human touch, champion digital democracy, learn for a lifetime, integrate our colleges, welcome dynamic balance, embrace expanding markets, and dog the details. It is often these simple truths that anchor our efforts forcefully to our highest purpose.

\section{J. Vision Exciting Horizons}

What a great time it is to be an educator. It is not hyperbole to say that there has never been a time when education has been as essential and accessible, thanks in no small part to asynchronous learning tools. The articles that follow bring these facts into clear relief. The question for us now is what can we do as we take bold steps down the road ahead? Can we open the doors of the community college even wider? Can we improve the learning experience even more? Can we so customize learning that it efficiently and effectively engages students with little to no bureaucracy or wasted time? Can we inspire more civic participation and involvement? Can we drive the engine of our economy? Can we help more people launch their own learning journeys? And in so doing, can we help them live better, freer, and more fulfilled lives? Can we? Of course, we don't have the answers; but we revel in the questions.

\section{REFERENCES}

1. American Association of Community Colleges. Trends and Statistics. 2004. www.aacc.nche.edu.

2. Milliron, M. D. and de los Santos, G. E. Making the Most of Community Colleges on the Road Ahead. Community College Journal of Research and Practice 28: 105-122, 2004.

3. Milliron, M. D. and Miles, C. Taking a Big Picture Look at Technology, Learning, and the Community College. Mission Viejo: League for Innovation in the Community College, 2000.

4. O'Banion, T. A Learning College for the 21st Century. Mission Viejo: ACE/Oryx Press, 1997.

5. Milliron, M. D. and Leach, E. R. Community Colleges Winning through Innovation: Taking on the Changes and Choices of Leadership in the Twenty-First Century. A Special Edition Leadership Abstracts commissioned by IBM and PeopleSoft. 1997.

6. Milliron, M. D. and Miles, C. L. AHA! Making the Connection Between the Internet and Learning. Learning Abstracts 3(1): January 2000. 
7. O'Banion, T. and Milliron, M. D. College Conversations on Learning. Learning Abstracts 4(5): 2001.

8. Roueche, J. E., Milliron, M. D., and Roueche, S. D. The Power of Practical Magic: Perspectives from Teaching Excellence Award Recipients. Celebrations. University of Texas at Austin's NISOD Publications, 2003.

9. Wilson, C. D. The Community College as a Learning-centered Organization. In Thomas, N., Lorenzo, A. L., and M. D. Milliron, M. D. (Eds.), Perspectives on the Community College: A Journey of Discovery. Phoenix: League for Innovation in the Community College, 23-26, 2003.

10. de los Santos, G. E., de los Santos, A. G., and Milliron, M. D. From Digital Divide to Digital Democracy. Phoenix: League for Innovation in the Community College, 2003.

11. Milliron, M. D. and Miles, C. Education in a Digital Democracy: Leading the Charge for Learning about, with, and beyond Technology. Educause Review (November-December 2000).

12. Milliron, M. D. and Miles, C. L. Technology, Learning, and Community (TLC) in Instruction: Perspectives from Community College Teaching Excellence Award Recipients. Monograph, Mission Viejo: League for Innovation in the Community College, 1998. 